\title{
The pulse oximeter: learning to punch above its weight?
}

\section{*Andrew RL Medford}

Department of Respiratory Medicine, Allergy and Thoracic Surgery, Institute for Lung Health, Glenfield Hospital, University Hospitals of Leicester NHS Trust, Leicester, UK.

*Correspondence:

Dr Andrew RL Medford

Interventional Pulmonology Fellow, Department of Respiratory Medicine, Glenfield Hospital,

University Hospitals of Leicester NHS Trust,

Leicester LE3 9QP, Leicestershire, United Kingdom.

Tel: +44 (0)1162502766

Fax: +44 (0)1162502787

E-mail: andrewmedford@hotmail.com

Keywords: pulse oximetry, hypoxaemia, primary care

31st January 2009

(C) 2009 General Practice Airways Group. All rights reserved

\section{Dear Sir,}

Is there a more valuable pulmonological tool for the general practitioner (GP) or respiratory physician - considering its weight, size and cost - than the portable pulse oximeter? At only 60 grams in weight, $60 \mathrm{~cm}^{3}$ in size and costing $£ 45$, it successfully beats the peak flow meter, portable spirometer and stethoscope. A recent survey of 47 respiratory specialist registrars revealed that $21.3 \%$ had acquired or were about to acquire their own portable oximeter (unpublished observations), as compared to 2004 when a similar survey revealed that only $4.3 \%$ of specialty trainees had one (odds ratio $6.1,95 \%$ confidence intervals 1.3 to 29.5 , $p=0.03$, Fishers exact test). This would suggest that specialty trainees are starting to think likewise. Respiratory specialist nurses in 'hospital at home' teams are usually identified by the oximeter on their belt or around their neck before one even views their identification badge. Even $10 \%$ (albeit only from a survey of 20) of the last pulmonary rehabilitation patients attending their COPD lecture had their own oximeter and could provide anecdotal experience of personal benefit.

The limitations of the pulse oximeter are well known. It cannot assess ventilation, cannot detect hyperoxia, and does not measure $\mathrm{PaO} 2$. It is also subject to error in the presence of abnormal haemoglobin, hypoperfusion, hypothermia, gross anaemia, venous congestion, nail polish and vital dyes. However, provided these limitations are taken into account, pulse oximetry can be an extremely useful adjunct to clinical acumen in primary care (as well as its more ubiquitous use in secondary care). Primary care and community based studies have demonstrated its potential value in detecting hypoxaemia in COPD patients (detecting 13\% of unexpected hypoxaemia in a cohort of COPD patients requiring admission or assessment ${ }^{1}$ ), predicting the development of community acquired pneumonia in nursing home residents, ${ }^{2}$ being a sensitive tool for selecting patients who require long-term oxygen therapy assessment with arterial blood gases ${ }^{3}$ (although its specificity is acknowledged to be limited ${ }^{4}$ ), and detecting unsuspected exercise-induced hypoxaemia in the community in the assessment of possible pulmonary embolism or other clinically significant lung disease or cardiac shunt. ${ }^{5}$

General practitioners, respiratory physicians, specialist nurses and patients have reached a consensus here. Let us celebrate the pocket pulse oximeter. At a weight of 60 grams, long may it continue to punch above its weight...

\section{Conflict of interest declaration}

None to declare.

\section{References}

1. Jones K, Cassidy P, Killen J, Ellis H. The feasibility and usefulness of oximetry measurements in primary care. Prim Care Resp J 2003;12(1):4-6

2. Kaye KS, Stalam M, Shershen WE, Kaye D. Utility of pulse oximetry in diagnosing pneumonia in nursing home residents. Am J Med Sci 2002;324(5):237-42. doi:10.1097/00000441-200211000-00001

3. Roberts CM, Franklin J, O'Neill A, et al. Screening patients in general practice with COPD for long-term domiciliary oxygen requirement using pulse oximetry. Respir Med 1998;92(11):1265-8. doi:10.1016/S09546111(98)90226-8

4. Roberts CM, Bugler JR, Melchor R, Hetzel MR, Spiro SG. Value of pulse oximetry in screening for long-term oxygen therapy requirement. Eur Respir J 1993;6(4):559-62.

5. Rossdale M, Harvey JE. Diagnosing pulmonary embolism in primary care. BMJ 2003;327(7411):393. doi:10.1136/bmj.327.7411.393 